\title{
Analysis and performance of novel and highly efficient electronic ballast operating at unity-power-factor
}

\author{
V B BORGHATE, H M SURYAWANSHI and G A DHOMANE
}

Electrical Engineering Department, Visvesvaraya National Institute of Technology, South Ambazari Road, Nagpur 440011

e-mail: vijay_borghate@rediffmail.com; hms_1963@rediffmail.com; g_dhomane@rediffmail.com

\begin{abstract}
This paper presents the electronic ballast, in which the coupling inductors are used to inject the current to the dc-bus capacitors, to boost the dc-bus voltage and to filter out the ripples from input line current. The current injection coupling inductor injects its stored energy to the dc-bus capacitors in every switching half cycle. Whereas, the boost coupling inductor keeps the dc-bus voltage always above the peak of ac input voltage. Therefore, the proposed ballast maintains unitypower-factor and high efficiency with ripple-free input current over wide range of input line voltage in case of worst regulation. A symmetrical half-bridge inverter is used to drive the fluorescent lamps. The experimental results of the laboratory prototype ballast for $2 \times 36 \mathrm{~W}$ fluorescent lamps operating at $50 \mathrm{kHz}$ are presented.
\end{abstract}

Keywords. Coupling-inductor; power-factor-correction; unity-power-factor; zero-voltage-switching.

\section{Introduction}

High frequency (HF) electronic ballasts (EB) are used now widely to replace the fluorescent lamps, because these ballasts have the additional features like no flickering or stroboscopic effect, silent operation, high efficiency, high-power-factor (HPF), instant start, low harmonic distortions (THD), and low EMI. In the basic circuit of electronic ballast, the power conversion takes place in two steps as $50 \mathrm{~Hz}$ ac-to-dc and dc-to-HF ac. Owing to use of uncontrolled rectifier with large electrolytic capacitor, the input line current of electronic ballast contains significant harmonics, and therefore, results in poor input power factor. To achieve the HPF with low THD specified by IEC Standards on EMC, additional power-factor-correction (PFC) circuit is required. Therefore, large input LC filter is added, resulting in two-stage topology (Almeida et al 1998; 2000). In such circuits, the dc voltage is maintained above the double value of input peak voltage, which resulted in high voltage stress on the power switches, reduction in efficiency and reliability besides increase in cost. The reported efficiency, power factor and THD in these papers are up to $89 \%, 0.99$ and 17\% respectively. By integrating the conventional PFC circuit with the inverter switches resulted in single-stage topology (Brumati et al 2005; De et al 1998; Do \& Kwon 2003) in which the reported values of efficiency, 


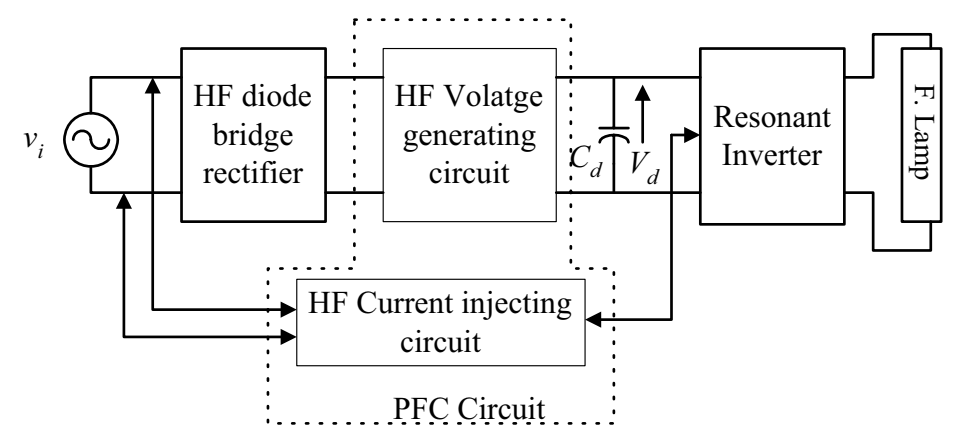

Figure 1. Schematic diagram of proposed circuit.

power factor and THD are up to 90\%, 0.99 and 10\% respectively. But problem of high dc-link voltage was unsolved. This problem has been overcome by using unconventional PFC circuit in the single-stage electronic ballast (Kazimierczuck et al 1993; Lin \& Chen 1998; Spangler $\&$ Benera 1991). The dc-link voltage is kept slightly above the peak of input ac voltage to achieve the same effects, resulted in main advantage of low stress on the switches. The reported efficiency, power factor and THD are 85-94\%, 0.97-0.999 and 4.1-15\% respectively. Borghate et al 2006, reported operation of single-stage electronic ballast for fluorescent lamp. However, only performance of input line parameter is investigated.

In this paper, the analysis, performance and design of components of a single-stage electronic ballast based on unconventional PFC circuit and symmetrical half-bridge inverter is presented in detail. The detailed experimental results along with characteristics of fluorescent lamp are also presented. Its schematic diagram is shown in figure 1 . The boost coupling inductor is used as a HF voltage generating circuit, and is connected between the ac input voltage source and the dc-link capacitor. This circuit generates the HF voltage of magnitude inversely proportional to the instantaneous value of the input ac voltage. Therefore, the dclink capacitors are always charged to the instantaneous value of input ac voltage plus HF generated voltage. This results in ripple free constant dc-link voltage over the entire input ac cycle. To maintain the energy of the dc-link capacitors, another coupling inductor is used as a HF current injecting circuit, which injects the energy in every half switching cycle. As such no additional filter circuit is required for this proposed circuit, but due to non-ideal components, a coupling inductor of small value is used at the input of the circuit to filter out the harmonics. The main advantage of this topology is that, over the wide range of input voltage, the power factor is maintained at unity with ripple free input current. It requires low value of dc-bus electrolytic capacitors and no need of dc-blocking capacitors in the inverter output circuit. Due to low components count, the circuit is cost effective with high reliability. The ripple free perfectly sinusoidal HF current flows through the fluorescent lamps; therefore, prolongs the lamp life.

\section{Operation of proposed circuit}

The proposed electronic ballast and its equivalent circuits are shown in figures 2 and 3 respectively. The PFC circuit consists of filter capacitors $C_{1}-C_{2}$, current injecting coupling inductor $L_{j}$ and boost coupling inductor $L_{b}$. The two identical inductors $L_{1}-L_{2}$ of $L_{j}$ inject their stored energy equally to the dc-bus capacitors $C_{d 1}-C_{d 2}$ besides input ac-source during 


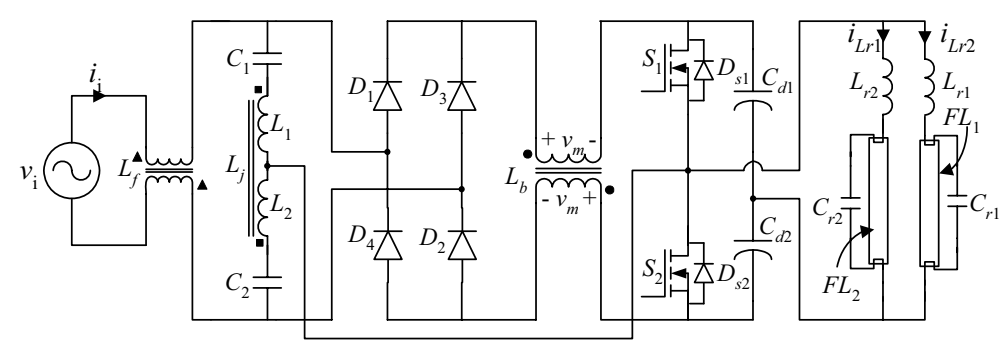

Figure 2. Circuit of proposed electronic ballast for two parallel-connected fluorescent lamps.

the some part of the half switching cycle, and restore-back their energy during another time period of the same half switching cycle. The values of these inductors are small compared to the boost inductor used in the PFC circuits of (De et al 1998, Almeida et al 1998) and self-leakage inductances of coupling inductor in (Do \& Kwon 2003). The capacitors $C_{1}$ and $C_{2}$ are identical and sufficiently large, maintain the constant voltage across them at $d v_{i}$ during the whole switching cycle, since the switching frequency $f_{s}$ is very large as compared to input line frequency $f$. These capacitors act as the filters for the inductor currents $i_{L 1}$ and $i_{L 2}$.

The coupling inductor $L_{b}$ at the output of rectifier is used to boost the dc-bus voltage $V_{d}$ and to filter out the HF ripples. As shown in figure 3, like a transformer, $L_{b}$ has two ideal windings $\left(w_{1}\right.$ and $\left.w_{2}\right)$ and a magnetizing inductance $L_{m}$. The $w_{1}$ and $w_{2}$ carry the equal currents, whereas $L_{m}$ carries the difference of the currents $\left(i_{1}-i_{2}\right)$. The $L_{m}$ can be referred to the either side of $L_{b}$, whichever side carries the higher current. The required value of magnetizing inductance, in this proposed topology, is very less compared to (Do \& Kwon 2003); therefore the possibility of saturation of core is minimized. The high frequency voltage $v_{m}$ induced in $L_{b}$, as in Almeida et al (1998), helps to boost the dc-bus voltage $V_{d}$ always above the peak value of input ac-voltage $V_{p}$, which ensures the discontinuous current mode (DCM) operation of boost converter $\left(i_{C d 1}-i_{C d 2}\right)$ during the entire cycle of ac-mains. The $V_{d}$ can be maintained less than $400 \mathrm{~V}$ dc in case of $230 \mathrm{~V}$ applications. At this voltage, rms value of MOSFETs current is lower, results in higher efficiency than other topologies; whereas, the conventional boost circuit requires $V_{d}$ greater than twice of $V_{p}$. In the proposed ballast, no additional wave shaper is required, but the components used are not ideal ones, therefore a

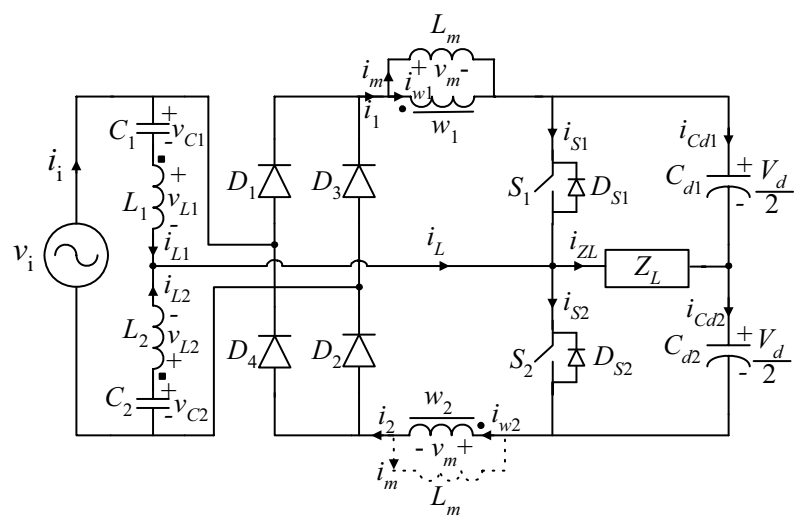

Figure 3. Equivalent circuit diagram of proposed electronic circuit. 
small filter coupling inductor $\left(L_{f}\right)$ is used at the input of circuit to achieve the ripple free input line current.

The inverter output circuit consists of parallel-connected two series-parallel resonant circuits. It is represented by equivalent impedance $Z_{L}$. To achieve the inherent zero-voltageswitching (ZVS) of switches, the switching frequency is to be kept slightly greater than the natural resonance frequency $f_{0}$. The duty ratio $d$ is kept at 0.5 for symmetrical PWM.

The above discussion is summarized as follows:

$$
\begin{aligned}
& L_{1}=L_{2}, C_{1}=C_{2}, C_{d 1}=C_{d 2} \\
& i_{w 1}=i_{w 2}, i_{m}=i_{1}-i_{2}, i_{L}=i_{L 1}+i_{L 2}, i_{L 1}=i_{L 2}=i_{L} / 2 \\
& v_{w 1}=v_{w 2}=v_{m}, v_{i}=v_{C 1}+v_{C 2}, v_{C 1}=v_{C 2}=d \quad v_{i}=0 \cdot 5 v_{i} \\
& v_{L 1}=-v_{L 2}, V_{d 1}=V_{d 2}=V_{d} / 2, V_{d}>V_{p} .
\end{aligned}
$$

\section{Modes of operation}

The proposed circuit goes through eight different modes in an every switching time period $T_{s}\left(1 / f_{s}\right)$ under steady-state condition. But, only first-four different modes in a half switching cycle are explained here. The remaining four modes of the next half cycle are equivalent to these first-four modes. The equivalent circuit diagrams of different modes and its idealized key waveforms are shown in figures 4 and 5 respectively.

Prior to start of mode-1, the currents $i_{L 1}$ freewheels through $S_{2}, L_{m}, D_{2}$, ac-mains, $C_{1}$ and $L_{1}$ at $I_{L} / 2$, whereas $i_{L 2}$ freewheels through $S_{2}, L_{m}, D_{2}, C_{2}$ and $L_{2}$. The diodes $D_{1}, D_{3}$ and $D_{4}$ and MOSFET $S_{1}$ are off. The DC bus capacitor current $I_{C d 1}$ is zero, whereas $C_{d 2}$ is supplying current to the resonant circuit through $S_{2}$ at $I_{Z L}$.

\subsection{Mode-1 $\left(t_{0}-t_{1}\right)$}

As shown in figure 4a, at $t_{0}$, the switch $S_{2}$ is turned off and the diodes $D_{S 1}$ and $D_{1}$ start conducting as soon as voltage across the switch $S_{1}$ falls to zero. The inductors $L_{1}$ and $L_{2}$ transfer their stored energy through $D_{S 1}$ to $C_{d 1}$ and $C_{d 2}$ along with ac-mains through $D_{1}$ during this mode. This mode ends at $t_{1}$, when inductor currents $i_{L 1}$ and $i_{L 2}$ decrease to zero.

\subsection{Mode-2 $\left(t_{1}-t_{2}\right)$}

The diode $D_{S 1}$ turns off at $t 1$, since $i_{L}$ becomes zero, and switch $S_{1}$ turns on as shown in figure $4 \mathrm{~b}$. Thus, inherent ZVS of $S_{1}$ is achieved. The inductors $L_{1}$ and $L_{2}$ restore their energy from $L_{m}$ through $S_{1}$ during this mode. Therefore, the currents $i_{L 1}$ and $i_{L 2}$ continue to vary as in mode-1, but opposite in direction. This mode ends at $t_{2}$, when charging current $I_{C d 1}$ decreases to zero.

\subsection{Mode-3 $\left(t_{2}-t_{3}\right)$}

This mode is similar to mode- 2 except that $C_{d 1}$ also starts supplying energy to $Z_{L}$ as shown in figure $4 \mathrm{c}$. At the end of this mode at $t 3$, the currents $i_{L 1}$ and $i_{L 2}$ reach to their peak values and the current $i_{C d 2}$ of another dc bus capacitor decreases linearly to zero. 

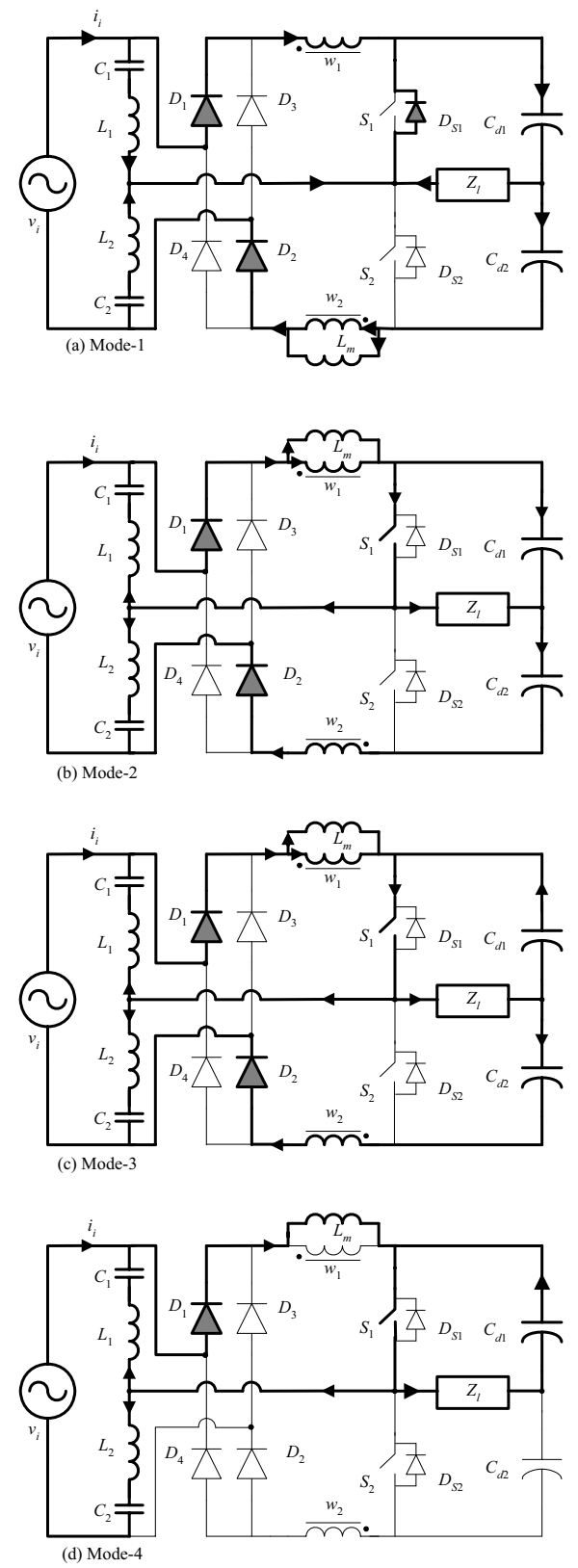

Figure 4. Operating modes.

\subsection{Mode-4 $\left(t_{3}-t_{4}\right)$}

As shown in figure $4 \mathrm{~d}$, diode $D_{2}$ turns off at $t_{3}$, as current $i_{C d 2}$ is zero. The $L_{m}$ is greater than $L_{1}$ and $L_{2}$, therefore, the currents $i_{L 1}$ and $i_{L 2}$ clamp at their respective peak values as on $t_{3}$, and the additional energy of $L_{m}$ is returned to the ac source during this mode. This mode ends at $t_{4}$, when energy of $L_{m}$ is exhausted.

Similar operation takes place in another four modes during the next half switching time period. 


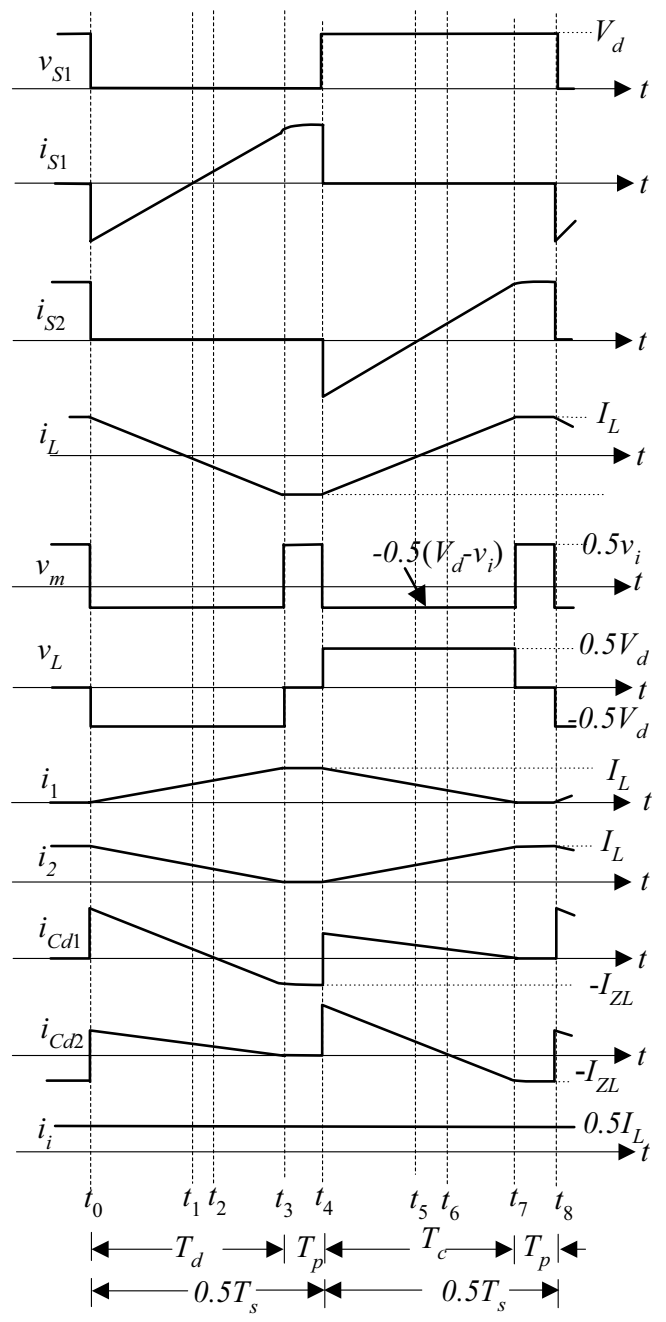

Figure 5. Idealized key waveforms.

\section{Analysis of circuit}

\subsection{Analysis of modes}

During modes 1 to 3, the voltages and currents of boost and injecting inductors are

$$
\begin{aligned}
& v_{m}=-\frac{V_{d}-v_{i}}{2} \\
& v_{L 1}=-\frac{V_{d}-(1-2 d) v_{i}}{2} \\
& i_{L 1}(t)=+\frac{I_{L}}{2}-\frac{V_{d}-(1-2 d) v_{i}}{2 L_{1}}\left(t-t_{0}\right)
\end{aligned}
$$




$$
i_{m}=-i_{L}, \text { and }
$$

the input current is

$$
i_{i}=i_{1}+i_{L} / 2=i_{2}-i_{L} / 2
$$

As shown in figure 5 , the current $i_{1}$ increases linearly from 0 (at $t_{0}$ ) to maximum value $I_{L}$ (at $t_{3}$ ), whereas the current $i_{2}$ decreases linearly from $I_{L}$ (at $\left.t_{0}\right)$ to $0\left(\right.$ at $\left.t_{3}\right)$ as

$$
\begin{aligned}
& i_{1}(t)=0+\frac{I_{L}}{\left(t_{3}-t_{0}\right)}\left(t-t_{0}\right), \text { and } \\
& i_{2}(t)=I_{L}-\frac{I_{L}}{\left(t_{3}-t_{0}\right)}\left(t-t_{0}\right) .
\end{aligned}
$$

Therefore, from (7) to (9), the instantaneous average value of input current $i_{i}$ during the time period $\left(t_{0}-t_{3}\right)$ is the sum of the average values of $i_{1}$ and $i_{L} / 2$,

$$
i_{\text {i av }}=i_{1 \text { av }}+\left(i_{L} / 2\right)_{a v}=I_{L} / 2+0=I_{L} / 2 \text {. }
$$

During mode 4,

$$
\begin{aligned}
& v_{L 1}(t)=v_{L 2}(t)=0, \quad v_{m}(t)=v_{C 1}=d v_{i}=0.5 v_{i} \\
& i_{1}=i_{m}=-i_{L}=+I_{L}, \\
& i_{i}=I_{L} / 2 .
\end{aligned}
$$

From (10) and (13), it is seen that the input current $i_{i}$ maintains constant value at $I_{L} / 2$ during the whole switching cycle.

\subsection{Calculations for $L$ and input current $i_{i}$}

By applying an equal area criteria to the $v_{L 1}$ and $v_{m}$ during one switching period, and defining the inductor current linearly decreasing and increasing time periods $\left(t_{0}\right.$ to $\left.t_{3}\right)$ and $\left(t_{4}\right.$ to $\left.t_{7}\right)$ as $T_{d}$ and $T_{c}$ respectively,

$$
\begin{array}{r}
\text { For } v_{L 1}: \frac{V_{d}-(1-2 d) v_{i}}{2} T_{d}=\frac{V_{d}+(1-2 d) v_{i}}{2} T_{c} . \\
\text { For } v_{m}: \frac{V_{d}-v_{i}}{2}\left(T_{d}+T_{c}\right)=d \cdot v_{i}\left[\left(d \cdot T_{s}-T_{d}\right)+\left(d \cdot T_{s}-T_{c}\right)\right] .
\end{array}
$$

Solving above two equations for $T_{d}$ and $T_{c}$, gives

$$
T_{d}=\frac{2 d^{2} T_{s} v_{i}}{V_{d}-(1-2 d) v_{i}}, \text { and } T_{c}=\frac{2 d^{2} T_{s} v_{i}}{V_{d}+(1-2 d) v_{i}} .
$$

The inductor current $i_{L 1}$ given by (5) is zero at $T_{d} / 2$ and $T_{c} / 2$ respectively, since it varies linearly. Therefore, the maximum value of sum of inductor currents is,

$$
I_{L}=\frac{d^{2} T_{s} v_{i}}{L_{1}} .
$$


From (10) and (11) and taking $L_{1}=L_{2}=L$, the input current is

$$
i_{i}=\frac{I_{L}}{2}=\frac{d^{2} T_{s} v_{i}}{2 L}
$$

where, $v_{i}$ is the instantaneous value of input voltage during that switching period.

From (18), it is evident that the input current $i_{i}$ varies with the input voltage $v_{i}$ at given value of current injecting inductors $L_{1}$ and $L_{2}$, duty ratio $d$, and switching frequency $f_{s}\left(1 / T_{s}\right)$; and it does not contain any other components than fundamental.

The input ac-voltage is

$$
v_{i}(t)=V_{p} \sin 2 \pi f t,
$$

where, $f$ is the frequency of ac mains.

Therefore, the input ac current is, from (18),

$$
i_{i}(t)=\frac{d^{2} T_{s} V_{p}}{2 L} \sin 2 \pi f t=I_{p} \sin 2 \pi f t,
$$

Where, peak value of input current is $I_{p}=\frac{d^{2} T_{s} V_{p}}{2 L}$.

From (20), it is evident that the proposed ballast operates at unity-power-factor.

The input power is,

$$
P_{i}=\frac{1}{\pi} \int_{0}^{\pi} v_{i}(t) \cdot i_{i}(t) \cdot d(\omega t)=\frac{V_{p} I_{p}}{2}=\frac{d^{2} T_{s} V_{p}^{2}}{4 L}=\frac{d^{2} T_{s} V^{2}}{2 L} .
$$

Therefore, the value of inductors, $L=L_{1}=L_{2}$ is given by,

$$
L=\frac{d^{2} T_{s} V^{2}}{2 P_{i}}=\frac{\eta T_{s} V^{2}}{8 P_{o}},
$$

where $P_{o}, \eta$ and $V$ are the rated output power of the fluorescent lamp, efficiency of the ballast at rated output and rated rms input ac voltage respectively.

\subsection{Calculations for $L_{m}$ and dc-bus voltage $V_{d}$}

The inductance $L_{m}$ carries the flat top current of value $I_{L}$ during the freewheeling time period, $T_{p}=\frac{T_{s}}{2}-\left(T_{d}\right.$ or $\left.T_{c}\right)=\frac{T_{s}}{2}\left(1-\frac{v_{i}}{V_{d}}\right)$ at duty ratio $d=0 \cdot 5$, which varies with the instantaneous input voltage $v_{i}$ over the half cycle of ac mains from maximum $T_{s} / 2$ (approximately) at the valley point of pulsating rectified ac input to minimum at the peak of it. Therefore, the minimum value of $L_{m}$ is calculated as follows,

$$
L_{m \min }=\frac{v_{m \max } T_{s}}{2 I_{L}} .
$$

From equations (11), (17) and (23)

$$
L_{m \min }=\frac{d V_{p}}{2 f_{s} I_{L}} \approx \frac{d V_{d}}{2 f_{s} I_{L}}=L .
$$

From (17) and (24), the dc-bus voltage is

$$
V_{d}=\frac{L_{m}}{L} V_{p}
$$

That is to maintain the dc-bus voltage $V_{d}$ above the peak value of ac input voltage $V_{p}$ at duty ratio $0 \cdot 5$, the magnetizing inductance $L_{m}$ should be greater than the injecting inductors $L_{1}$ and $L_{2}$. 


\section{Design example}

The specifications of ballast are as follows;

Rated input voltage, $V=230 \mathrm{~V}(\mathrm{rms}), 50 \mathrm{~Hz}$

Operating input voltage range $=180-250 \mathrm{~V}(\mathrm{rms})$

Rating of fluorescent lamps, $P_{0}=2 \times 36=72 \mathrm{~W}$

Switching frequency, $f_{s}=50 \mathrm{kHz}$.

Based on the above specification and analysis, the inductors and capacitors are calculated as; assuming the expected efficiency of the ballast to be $93 \%$ at rated output power and 0.5 duty ratio, the value of current injecting inductors at $230 \mathrm{~V}$ is, $L_{1}=L_{2}=1.7 \mathrm{mH}$, The capacitors $C_{1}$ and $C_{2}$ are fixed at $0 \cdot 1 \mu \mathrm{F} / 400 \mathrm{~V}$ (polypropylene). For maintaining the sufficient light intensity $L_{1}=L_{2}=1 \mathrm{mH}$ and $L_{m}=1.1 \mathrm{mH}$ are selected.

The small value of input coupling inductor $L_{f}$ of $100 \mu \mathrm{H}$ is used further to minimize the HF switching ripples. The DC link capacitors $C_{d 1}$ and $C_{d 2}$ are selected as $22 \mu \mathrm{F} / 400 \mathrm{~V}$ (electrolytic). At switching frequency $f_{s}=50 \mathrm{kHz}$, the parameters of resonant circuit are $C_{r}=10 \mathrm{nF}$ (polypropylene), $L_{r}=1.35 \mathrm{mH}, f_{0}=43.15 \mathrm{kHz}, Z_{0}=369 \Omega$, and $R_{F L}=$ $313 \Omega$. Diodes $\left(D_{1}-D_{4}\right)$ : UF 5408 and MOSFETs $\left(S_{1}-S_{2}\right)$ : IRF 840.

\section{Experimental results}

A prototype of proposed electronic ballast circuit is built and tested in the laboratory. The experimental ac input line voltage $\left(v_{i}\right)$, current $\left(i_{i}\right)$ and dc link voltage $\left(V_{d}\right)$ waveforms at nominal voltage $230 \mathrm{~V}$ are shown in figure 6 . This figure shows that the proposed ballast operates at unity power factor, for which the dc-link voltage $\left(V_{d}\right)$ is just above the peak value $\left(V_{p}\right)$ of ac input voltage. The experimental waveform of HF generated voltage $\left(v_{m}\right)$ in the coupling inductor $L_{b}$ is given in figure 7 . It may be observed that the value of $v_{m}$ is large at zero crossing and small at peak of the ac input voltage. Therefore, the $V_{d}$ is maintained constant even at the valley of the input voltage. Figures $8 \mathrm{a}$ and $\mathrm{b}$ give the voltage $\left(v_{L j}\right)$ and current $\left(i_{L j}\right)$ waveforms of the current injecting inductor $L_{j}$ near peak and zero value of the ac input voltage respectively. The $L_{j}$ injects its stored energy to the dc-link capacitor in every half switching cycle, when $i_{L j}$ falls from its peak value (positive or negative) to zero. The proposed PFC circuit produces the HF voltage of constant magnitude $\left(v_{\text {rin }}\right)$ shown in figure 9 ,

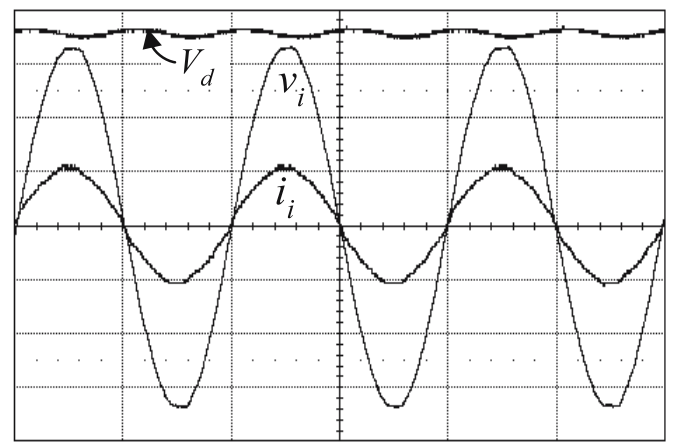

Figure 6. Experimental input voltage $\left(v_{i}\right)$ and current $\left(i_{i}\right)$ and dc-link voltage $\left(V_{d}\right)$ waveforms at $230 \mathrm{~V}$ : (100 V/div, $0.4 \mathrm{~A} / \mathrm{div}, 10 \mathrm{~ms} / \mathrm{div})$. 


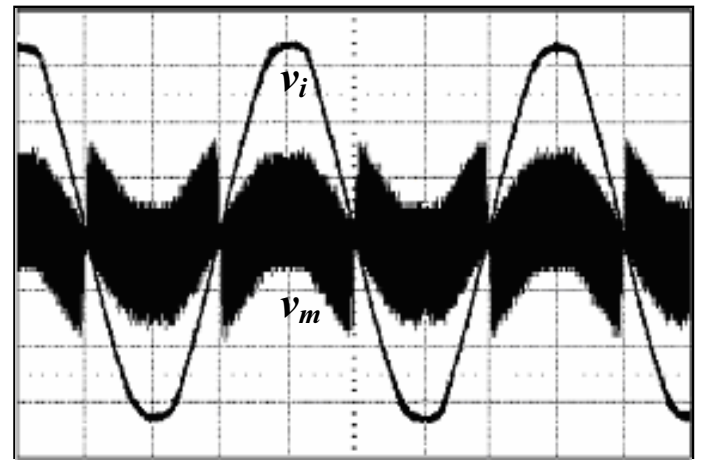

Figure 7. Experimental waveforms of input voltage $\left(v_{i}\right)$ and HF generated voltage $\left(v_{m}\right)$ in $L_{b}:(100 \mathrm{~V} / \mathrm{div}, 5 \mathrm{~ms} / \mathrm{div})$.

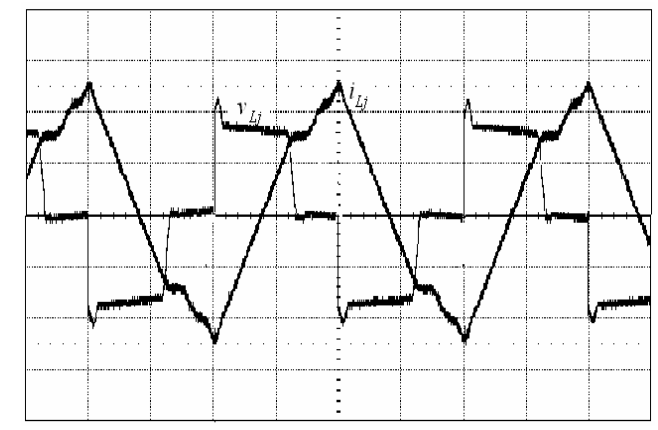

(a)

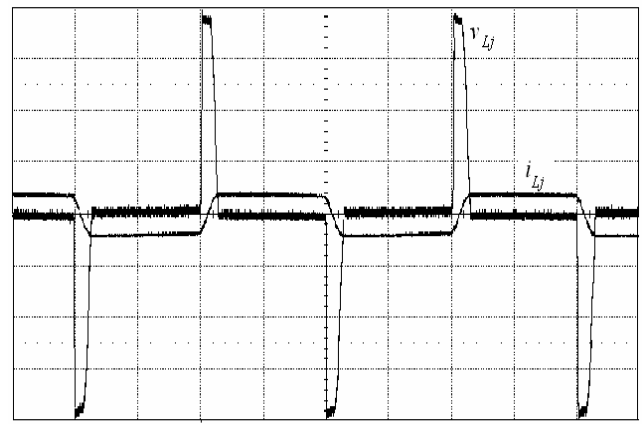

(b)

Figure 8. Experimental waveforms of voltage $\left(v_{L}\right)$ and current $\left(i_{L}\right)$ of $L_{j}$ at (a) Near peak of AC input voltage: (100 V/div, $0.2 \mathrm{~A} / \mathrm{div} ; 5 \mu \mathrm{s} / \mathrm{div}$.), (b) Near valley of AC input voltage: (50 V/div, $0.2 \mathrm{~A} / \mathrm{div}$; $5 \mu \mathrm{s} /$ div.).

over the input $50 \mathrm{~Hz}$ cycle, at the input of the diode bridge rectifier ensures the conduction of bridge at the valley point of the input voltage. The switch voltage $\left(v_{s}\right)$ and current $\left(i_{s}\right)$ waveforms shown in figure 10 indicate its ZVS operation.

Figure 11 gives the output waveforms of the electronic ballast circuit. Figure 11a indicates that the HF fluorescent lamps voltage $\left(v_{F L}\right)$ and current $\left(i_{F L}\right)$ are sinusoidal with minimum
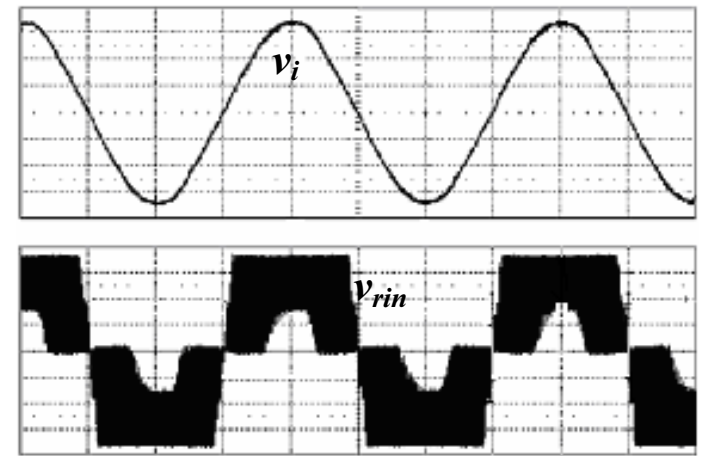

Figure 9. Experimental waveforms rectifier input voltage (vrin) and input voltage (vi): (100,V/div; 5 ms/div). 

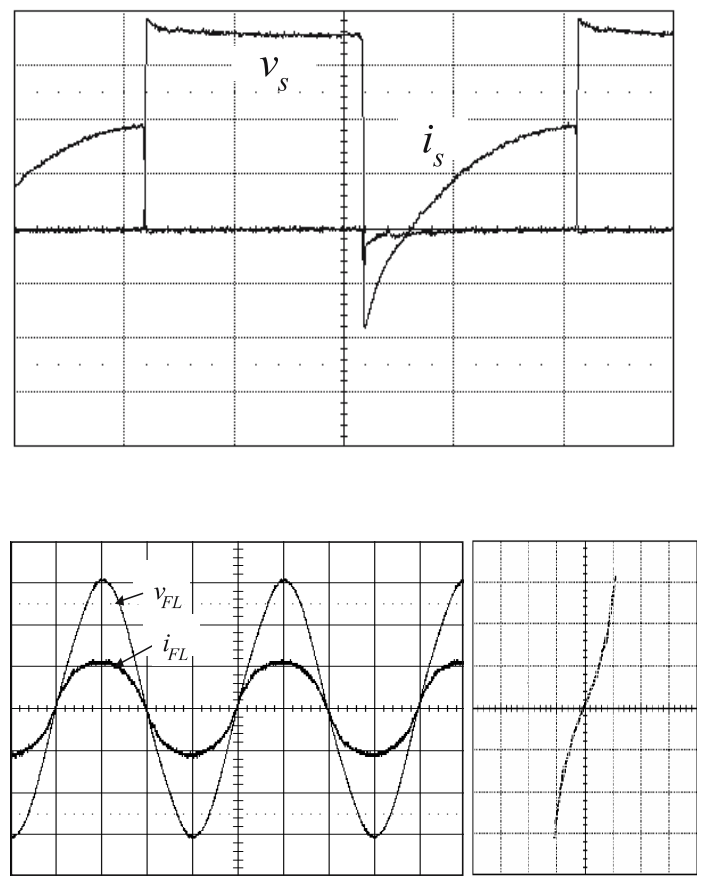

(a)

(b)

Figure 10. Experimental switch voltage $\left(v_{S}\right)$ and current $\left(i_{S}\right)$ waveforms. (100 V/div, $1 \mathrm{~A} / \mathrm{div}, 10 \mu \mathrm{s} / \mathrm{div})$.

Figure 11. (a) Experimental fluorescent lamp voltage $\left(v_{F L}\right)$ and current $\left(i_{F L}\right)$ at $50 \mathrm{kHz}$ : $(50 \mathrm{~V} / \mathrm{div}, 0.5 \mathrm{~A} / \mathrm{div} ; 5 \mu \mathrm{s} / \mathrm{div})$ and (b) V-I characteristic: (X-axis: $0.5 \mathrm{~A} /$ div; Yaxis: $50 \mathrm{~V} / \mathrm{div}$ ).

ripples, whereas its V-I characteristic is shown in figure 11b. These lamp results at HF are compared with the lamp results given in figure 12 at supply frequency $(50 \mathrm{~Hz})$. It is seen that the fluorescent lamp behaves as a nonlinear impedance at low frequency, whereas resistive load at HF. The envelope of lamp current $\left(i_{F L}\right)$ of $50 \mathrm{kHz}$ given in figure 13 is flat. The crest factor of lamp current is 1.4. Therefore, the electronic ballast helps to prolong the lifetime of the fluorescent lamps.

The experimental results are also obtained by changing the input voltage at $180 \mathrm{~V}, 200 \mathrm{~V}$ and $250 \mathrm{~V}$ with switching frequency $50 \mathrm{kHz}$ and duty ratio 0.5 . As shown in figure 14 , the proposed ballast maintains the power factor at unity with wide variation in input voltage. Experimentally it is seen that, with wide variation in input voltage, the efficiency of the ballast lies between $93-94.2 \%$ and the THD is not more than 3.2\% satisfying standards specified by IEC 61000-3-2.

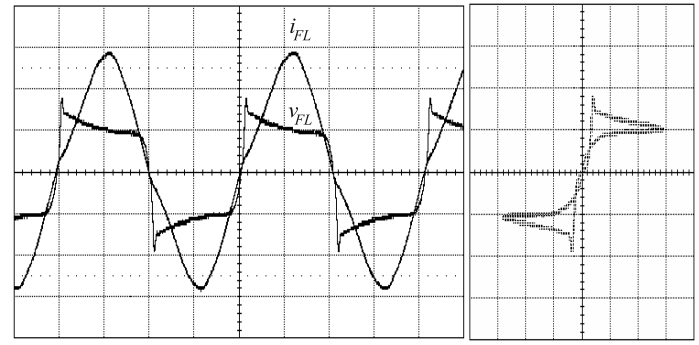

(a)
Figure 12. (a) Experimental fluorescent lamp voltage $\left(v_{F L}\right)$ and current $\left(i_{F L}\right)$ at $50 \mathrm{~Hz}$ : $(50 \mathrm{~V} / \mathrm{div}, 0.5 \mathrm{~A} / \mathrm{div} ; 5 \mathrm{~ms} / \mathrm{div})$ and (b) V-I characteristic: (X-axis: $0.5 \mathrm{~A} / \mathrm{div}$; Yaxis: $50 \mathrm{~V} / \mathrm{div}$ ). 


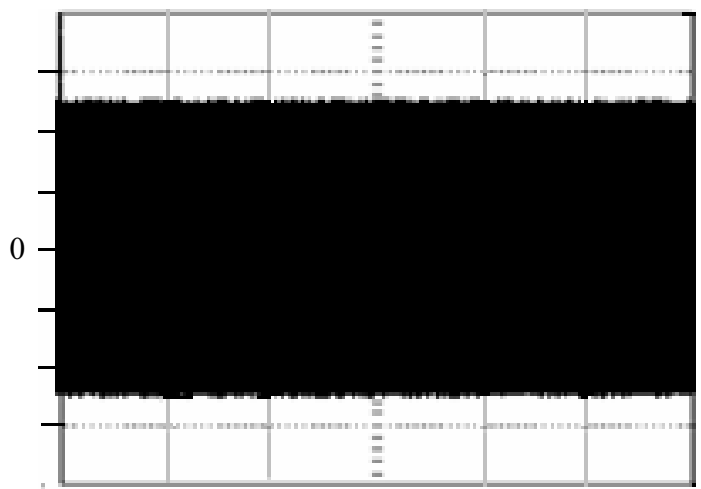

Figure 13. Envelope of lamp current $\left(i_{F L}\right)$ at $50 \mathrm{kHz}(0 \cdot 2 \mathrm{~A} / \mathrm{div})$.

It is also observed that incase of failure of one lamp, the dc-link voltage $V_{d}$ increases from $350 \mathrm{~V}$ to $464 \mathrm{~V}$, lamp current increases from 0.51 A to 0.695 A and switch current decreases from $2.43 \mathrm{~A}$ to $1.97 \mathrm{~A}$. Whereas, the input power factor is maintained at unity.

\section{Conclusion}

In this paper, ripple-free single-stage electronic ballast based on novel PFC circuit along with the symmetrical half bridge inverter topology was proposed. The coupling inductor connected

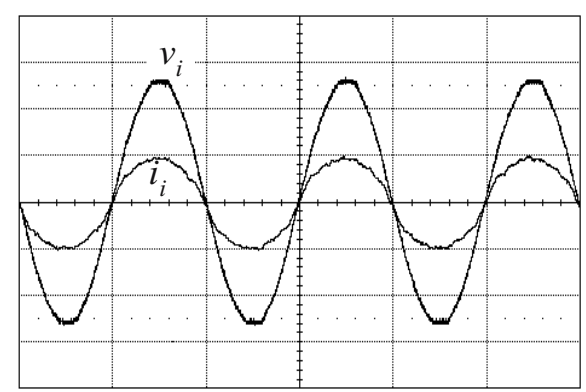

(a)

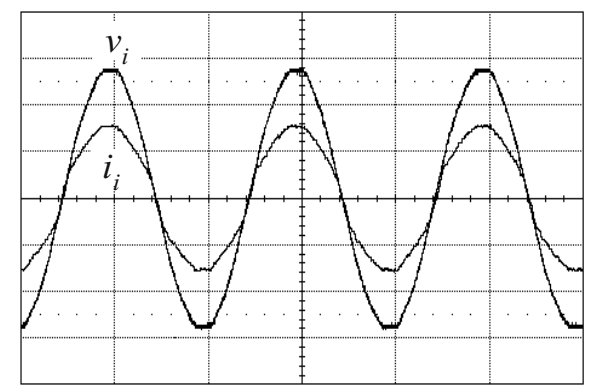

(b)

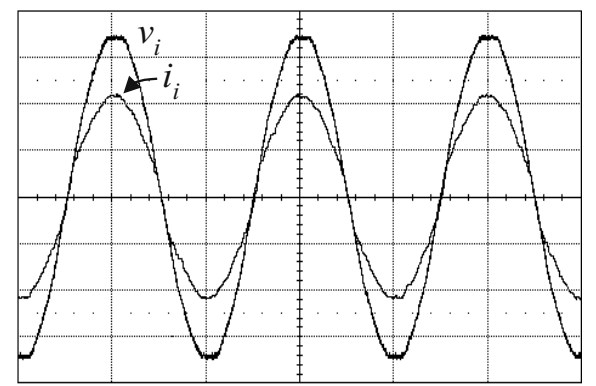

(c)

Figure 14. Experimental input voltage $\left(v_{i}\right)$ and current $\left(i_{i}\right)$ waveforms at (a) $180 \mathrm{~V}$, (b) $200 \mathrm{~V}$, (c) $250 \mathrm{~V}:(100 \mathrm{~V} / \mathrm{div}, 0 \cdot 2 \mathrm{~A} / \mathrm{div}, 10 \mathrm{~ms} / \mathrm{div})$. 
after the rectifier helps to boost the dc-link voltage above the peak of input voltage and also reduces the HF switching ripples. Two smaller dc-link capacitors are required as compared to single large capacitor with no additional dc blocking capacitors in the inverter circuit.

Based on the design, the laboratory prototype is built and tested for $(2 \times 36 \mathrm{~W})$ fluorescent lamps operating at $50 \mathrm{kHz}$ with mains $230 \mathrm{~V}, 50 \mathrm{~Hz}$. The proposed single-stage electronic ballast works at UPF with high efficiency and low THD over wide range of input voltage. Therefore, this topology is more useful in the system where wide fluctuation in the voltage takes place.

\section{References}

Almeida M Co, Simonetti D S L, Vieira J L F 1998 High-power-factor electronic ballast operating in critical conduction mode. IEEE Trans. power Electron. 13: 93-101

Almeida M Co, Simonetti D S L, Vieira J L F 2000 High-power-factor electronic ballast based on a single power processing stage. IEEE Trans. Ind. Electron. 47: 809-820

Borghate V B, Suryawanshi H M, Ramteke M R, Renge M M 2006 Electronic ballast with unity power factor based on current injection technique. $37^{\text {th }}$ IEEE International Power Electronics Specialist Conference-PESC-06, Jeju, Corea, 3314-3319

Brumatti M, Almeida M Co, Simonetti D S L, Vieira J L F 2005 Single stage self-oscillating HPF electronic ballast. IEEE Trans. Ind. Appl. 41: 735-741

De Oliveira R, Brioschi, Vieira J L F 1998 High power factor electronic ballast with constant DC-link voltage. IEEE Trans. Power Electron. 13: 1030-1037

Do H L, Kwon B H 2003 Single-stage line-coupled half-bridge ballast with unity power factor and ripple-free input current using coupled inductor. IEEE Trans. Ind. Electron. 50: 1259-1266

Kazimierczuk M K, Szaraniec W 1993 Electronic ballast for fluorescent lamp. IEEE Trans. Power Electron. 8: 386-395

Lin C S, Chen C L 1998 Single-switch soft-switching electronic ballast with high input power factor. IEE Proc. Electr. Power Appl. 145: 345-350

Spangler J, Behera A K 1991 Power factor correction techniques used for fluorescent lamp ballast. in Conf. Rec. IEEE-IAS Annaul Meeting 1836-1841 